\title{
BMJ Open Individual-level and community-level factors associated with the family planning use among pastoralist community of Ethiopia: a community- based cross-sectional study
}

\author{
Mussie Alemayehu (D , , ${ }^{1}$ araya Abrha Medhanyie, ${ }^{2}$ Elizabeth Reed, ${ }^{3}$ \\ Afework Mulugeta ${ }^{2}$
}

To cite: Alemayehu M, Medhanyie AA, Reed E, et al. Individual-level and communitylevel factors associated with the family planning use among pastoralist community of Ethiopia: a community-based cross-sectional study. BMJ Open 2020;10:e036519. doi:10.1136/ bmjopen-2019-036519

- Prepublication history for this paper is available online. To view these files, please visit the journal online (http://dx.doi. org/10.1136/bmjopen-2019036519).

Received 19 December 2019

Revised 07 May 2020

Accepted 18 July 2020

\section{Check for updates}

(C) Author(s) (or their employer(s)) 2020. Re-use permitted under CC BY-NC. No commercial re-use. See rights and permissions. Published by BMJ.

${ }^{1}$ Public Health, Mekelle University College of Health Sciences, Mekelle, Ethiopia ${ }^{2}$ School of Public Health, Mekelle University, Mekelle, Tigray, Ethiopia

${ }^{3}$ San Diego State University, San Diego, California, USA

Correspondence to Dr Mussie Alemayehu; mossalex75@gmail.com

\section{ABSTRACT}

Objective The study aimed to identify the effects of the individual-level and community-level factors on the use of family planning (FP) among married women in the pastoralist community of Ethiopia.

Design A community-based cross-sectional study was conducted in September 2018. Data were analysed using $R$ software. To determine the fixed effect of individuallevel and community-level factors of FP use, a two-level mixed-effects logistic regression was used. The result was described using the Adjusted OR (AOR), and the variance partition coefficient.

Setting and participants Afar, Ethiopia (2018; $n=891$ ) married women of reproductive age (15-49) years.

Primary outcome measures FP use or non-use. Results The current use of FP was $18.7 \%$ (16.31\%$21.43 \%)$. Women who need to walk 1 hour and more to the nearest health facility (AOR $0.14,95 \% \mathrm{Cl} 0.05$ to 0.3 ), have ANC visit of 4 and above (AOR 6.02, 95\% Cl 1.74 to 20.8), had their last birth at a health facility (AOR 2.71 $95 \% \mathrm{Cl} 1.27$ to 5.81 ), have five and more children (AOR $4.71,95 \% \mathrm{Cl} 1.86$ to 11.9$)$, have high knowledge on FP (AOR 2.74, 95\% Cl 1.11 to 6.74) and had high intentions to use FP (AOR 10.3, 95\% Cl 3.85 to 27.6) were more likely to report FP use. The magnitude of the effect of for FP use was smaller than that of 9 of the 13 individual factors. Apart from this $19.4 \%$ of the total variance in the odds of using FP attributed to between community difference (intraclass correlation coefficient $=0.194$ ). Regarding the community-level characteristics, clusters of having higher electronic media possession (AOR 2.84, 95\% Cl 1.2 to 6.72 ) and higher women decision making on FP (AOR $8.35,95 \% \mathrm{Cl} 2.7$ to 27.1 ) were significantly associated with increased FP use compared with clusters with lower reports of these aspects.

Conclusion FP use among the pastoralist community is influenced by both individual cluster/community-level characteristics or factors. Even though the effect of clustering in FP use was large in comparison with the unexplained between-cluster variation, it was lower than the individual-level factors.

Trail registrtion number NCT03450564
Strengths and limitations of this study

- Our study employs a robust methodology to analyse the data with consideration of the effect of both individual and community-level factors concerning family planning use.

- The result was described not only by the OR, proportional change of the variance, variance partition coefficient but also, a summary measures of the effect of cluster variables (interval $\mathrm{OR}$ and proportion of opposed $\mathrm{OR}$ ) and measures of components heterogeneity (median $\mathrm{OR}$ ) to make our result more informative and explanatory.

Due to the limited number of clusters, the desired effect is not explicitly described.

- The findings are limited to married women aged between 15 and 49 .

- The use of a cross-sectional study makes the examination of causal-effect relationships difficult.

\section{INTRODUCTION}

Despite low coverage or utilisation of contraceptive use in sub-Saharan Africa (SSA), the global modern contraceptive use increased, from $54 \%$ in 1990 to $57.4 \%$ in 2015 . In Africa, it increased from $23.6 \%$ to $28.5 \% .^{1}$ In addition to this, globally in 2018, nearly 214 million women of reproductive age in low/middleincome countries who want to avoid pregnancy are not using a modern contraceptive method. Such a number is high in Africa $24.2 \%{ }^{1}$ The main reasons are limited choice of methods, limited access to contraception, particularly among young people, poorer segments of populations or unmarried people; fear or experience of side effects; cultural or religious opposition; poor quality of available services; users and providers bias and gender-based barriers. Moreover, the proportion of women who use contraceptives 
and their barriers is very low and affected by multifaceted factors in the pastoral area. In SSA, pastoral and agropastoral communities account for 20 million and 240 million individuals, respectively. ${ }^{2}$ It is over a quarter of the total population and they cover an area of $43 \%$ of the continent's total landmass. ${ }^{3}$ Thus, a high proportion of women could benefit from having access to effective family planning (FP).

FP allows people to attain their desired number of children and determine the spacing of pregnancies. It is achieved through the use of contraceptive methods. ${ }^{1}$ Ethiopia, increased contraceptive prevalence rate (CPR) from 6.3 in 2000 to 41 in 2019. And such a number is not uniformly distributed between the agrarian and pastoralist region. ${ }^{45}$ The magnitude of FP among the pastoralist community was very low at $4.6 \% .{ }^{67}$ Increasing the current low CPR among the pastoralist community will contribute to a reduction in maternal and infant morbidity and mortality. Additionally, there could be socioeconomic benefits to women and the entire country. For instance, an economic benefit analysis study on FP in Ethiopia revealed that investing US $\$ 1$ to reduce TFR to 2.5 from 5.7 can save about US $\$ 53.42$ costs of health and education. ${ }^{8}$ Even though, a small pocket study in the pastoralist community of Ethiopia identifies the individual factors (monthly income, attitude, educational status, owning a radio, household asset availability, type of marriage in union (polygamous or monogamous), and the number of children wanted ${ }^{6-8}$ - they did not explore contextual/cluster-level factors associated with FP use in the pastoral area.

Furthermore, inability to identify cluster-level factors associated with FP do not give a complete picture on the dimension of FP use, it does not provide meaningful information to policymaker for intervention and does not show the clear gap for the future researchers. Hence, we hypothesised that FP use can be affected by both factors (individual and community). In light of this, this study aimed to examine the effects of individual and community-level characteristics and between-community differences on FP use. Additionally, most of the multilevel analysis results with a binary outcome including (FP use/ non-use) described by OR, the proportion of change in cluster variation (PCV), and variance partition coefficient (VPC) or intraclass correlation coefficient (ICC). Moreover, this study attempts to describe the finding in terms of measures of the effect of cluster-level variables (interval OR (IOR), proportion of opposed OR (POOR)) ) and measures of components of heterogeneity (median OR $(\mathrm{MOR}))$ to make the interpretation of the findings more informative and explanatory.

\section{METHODS}

\section{Study setting and study design}

As an end line for the cluster randomised controlled trial (CRT), to ascertain the effect of a community-based intervention for increasing FP use among pastoralist community a cross-sectional study was conducted. ${ }^{9}$ Its purpose was for identifying the individual and communitylevel factors in FP use. It was done in the Afar region of Northeastern Ethiopia in September 2018. Married women of reproductive age (15-49 years) were the source population, whereas women who were critically ill during data collection were excluded from the study.

\section{Sample size and sampling procedures}

The targets of inference for the findings were the entire pastoralist married women of reproductive-aged group (15-49) years. The sample size was selected using a cluster sampling technique. Initially, three districts namely Kori, Afambo and Mille were selected. On the second stage cluster/kebele which contains married women were selected. The sampling unit in this study included a total of 33 clusters and 891 married women. One cluster contains 27 married women. Hence, to approach eligible married women, a systematic sampling technique was employed. Based on the number of married women in the cluster, a sampling fraction was calculated and a random start number was identified to select the first household.

\section{Data collection procedure}

This data were collected as part of the end line CRT with trial registrationnumber of NCT03450564 ${ }^{9}$ - and the questions for the questionnaire were developed based on previous literature in the region. ${ }^{671011}$ Accordingly, a reliable and valid tool with a pastoralist context was developed Alemayehu, M., Medhanyie, A.A., Reed, E. et $a l$. Validation of family planning tool in the pastoralist community. Reprod Health 17, 123 (2020). https://doi. org/10.1186/s12978-020-00976-x. The tool was pretested in $45(5 \%)$ of married women. A total of six clinical nurse's data collectors and two supervisors participated during the data collection. Before the actual data collection, intensive training was given for the data collectors and supervisors on the purpose of the study, items, how to approach study participants, and how to use mobilebased applications. The data collectors and supervisors were assigned to the clusters of a given district. The data were collected using an electronically smartphone-based application open data kit (ODK). The collected data were sent to the Mekelle University (MU) server after checking for its completeness.

\section{Measurement}

The FP use (use or non-use) of the pastoralist married women was considered as the outcome variable.

\section{Individual-level variables}

Women's education was measured as a women's ability to read and write a simple sentence.

Intention to use FP was the motivational factors that influence FP use where the stronger the intention to perform the FP use, the more likely the FP use will be performed. ${ }^{12}$ A total of eight items that range from the lowest level (at this moment, I can list some benefits of FP use and I would gain if I use it) to the highest 
level of intention to use FP (It is expected that women in our community should use FP and so do I) was used. The response ranges from 1 (uncertain/disagree) to 3 (certain/agree). For the analysis purpose, intention to use FP was categorised into high and low intention to use FP based on the mean value.

Attitude and perceived behavioural control over FP use were collected as the constructs of the integrated behavioural model. Attitude towards FP use was composed of an expressional and instrumental attitude. Expressional attitude is the married woman's emotional response to the idea of performing FP use. A total of eight items with three response categories of 1 (unlikely/ unworthy) and 3 (likely/worthy) were used. Instrumental attitude is the married women's evaluation for the FP use. It is determined by belief about the outcomes of behaviour. Fourteen items with responses ranging from 1 (uncertain/unlikely) to 3 (certain/likely) were used. And perceived behavioural control over FP was composed of perceived control and self-efficacy. Perceived control is a married woman's perceived control over FP use. Ten items that scored from 3 (highly/agree) to 1 (does not matter/disagree) were used. Self-efficacy is the personal belief that married women can successfully perform an FP use under specified conditions. It was measured with seven items. Responses were coded as 1 (disagree) and 3 (agree). The items of expressional and instrumental attitude had a belief and evaluation components. Multiplying the belief response with its corresponding evaluation was made to create a continuous variable. And, the multiplied items of the response were summed up to form a continuous variable(attitude towards FP use). Moreover, the response of self-efficacy and perceived control was added to form a continuous variable). ${ }^{12}$

Time taken to reach the nearest health facility by walking was measured by asking the married women 'how long does it take you to walk to the nearest health facility'. And the response was categorised in minutes as 'less than 60 min (1 hour)', and 'greater than 60 min (1 hour)'.

Antenatal care (ANC) visit was measured by asking the married women of visit to a health facility for her recent pregnancy. The response was categorised as "no ANC visit', '1-3 ANC visits' and 'our and above ANC visits'. Place of delivery for last child was gathered by asking the married women of the place where she gave her last birth and the response was categorised as home or institutional delivery.

Knowledge of FP: The response to 13 items was labelled as 'alse', 'Not sure' and 'True'. And the response of these items was summed up to form one continuous variable. Accordingly, using the mean value, the response was categorised in to 'low knowledge on FP' and 'High knowledge on FP'. Examples of items include: 'FP use could cause menstruation disturbance', 'FP use could prevent daily activity', 'pill should be taken daily to prevent pregnancy', 'Depo-provera can prevent unwanted pregnancy for 3 months' and 'following FP use, pregnancy can return immediately'.

\section{Community-level variables}

Decision making on FP use was measured by asking the married women on the decision on FP. It was composed of four items namely who decides: to use/take, not to use/take, to stop the use of contraceptive and on the number of children a couple would have in the future. Its response was scored as 'women's only decision', 'joint decision' and 'husband only decision'. Items negatively worded were reversed scored. The response was summed up to form one continuous variable. Discussion among couples on FP use was measured by asking the married women whether they discussed or didn't discuss FP with their partner. The response was scored as 'no' or 'yes'. Women's norm on the number of children for couples to have includes a total of five items (eg, the total number of children a couple should have 2, 3, 4, 5 and 10). Its response was scored on a three-point Likert scale 1 (agree) to 3 (disagree). Then, the response was summed up to generate a continuous variable. Electronic media possession: the respondents were asked whether they have a radio, television or mobile phone. Its response was summed up to form one continuous. Health facility availability: it was measured by asking the respondents whether they have a health facility (health post or health centre) in their cluster/kebele. With this in mind, the above-listed community-level variables were created by aggregating the individual-level variables. Hence, based on the mean value of the response the variable was labelled as 'lower' and 'higher' categories for cluster who scored mean and below and above mean value, respectively.

\section{Data quality control}

In the beginning, intensive training was given for data collectors and supervisors. A strong follow-up and continuous support were given for the data collectors while they were in the field. The data were collected using an electronic-based application called an ODK. It was sent to MU server after its completeness was checked.

Verbal consent was secured from married women to collect the data. A one-page consent letter was attached to the cover page of each questionnaire as an information sheet which includes a detailed description about the benefit and risk of participating in the study, participation is voluntary, the right to withdraw from the study, identification of informant was possible only through specific identification numbers and the privacy of collected information. The data collected from the participants was kept confidential.

\section{Patient and public involvement \\ 'No patient involved'.}

\section{Data analysis}

The data collected through ODK was exported and analysed by R software V.3.6.1. At the initial step, exploratory data analyses include data coding and recoding, categorisation of continuous variables and construction of aggregate community-level variable (decision making on 
FP use, discussion with husband, health facility coverage, electronic media possession and women's norm on the number of children for couples to have) was made. Appropriate descriptive analyses of the data were computed over the different individual and community-level characteristics of the married women. The result was described and explained using text, frequency and percentage. Hence, the married women are nested within-cluster/kebele, a two-level mixed-effects regression model was employed to describe the individual and community level within and between cluster effect on FP use.

A two-level model was developed in which the individual women (level 1) are nested within the community (level 2) to estimate the effect of individual and community characteristics on FP use. Bivariate multilevel logistic regression analysis was performed between the individual and community characteristics with FP use to estimate the crude ORs. To reveal the adjusted effect size, multivariate two-level logistic regression analysis was performed to estimate the adjusted OR (AOR) for both the individual and community characteristics and to estimate the extent of random variations between communities.

\section{Model I (empty model)}

This was the first step in the multilevel model analysis to run the model without any factors. This aimed to test the random effect of the between-cluster variability. Derived from the between-cluster and within-cluster variability, the ICC was estimated to explain if the data justified to use a multilevel approach for analyses by depicting the level of variability between-clusters.

\section{Model II}

This model examined the effects of individual characteristics on FP use. Those individual-level variables which were statistically significant in the bivariate multilevel logistic regression analysis were included in this model.

\section{Model III}

It examined the effect of community variables on FP use. Those community-level variables which were statistically significant in the bivariate multilevel logistic regression analysis were included in this model. They were formed by aggregating the variable from the individual variables.

\section{Model IV}

It included both the individual and community-level characteristics which were statistically significant at model II and model III. This model allowed us to measure the effectiveness of both individual and community characteristics simultaneously. On the model with the consideration of the conditional or cluster-specific interpretation of the regression coefficient, a shrinkage factor was calculated for calculating marginal or population average regression coefficient and OR. It eases the interpretation of an association between the cluster-level variable and the outcome variable. As the shrinkage factors are very close to one, the population-average regression coefficients (and corresponding population-average ORs) will be very close to the conditional or cluster-specific regression coefficients and corresponding ORs. ${ }^{13} 14$

Moreover, a summary measure of the effects of clusterlevel variables: IOR and POOR were calculated. The IOR an interval covering the middle $80 \%$ of the distribution of such ORs. As every exposure category of the clusterlevel variable contains many clusters, when the residual cluster variance is large, then the distributions of the clusters around the average outcome in the different exposure categories overlap each other. Therefore, when performing pairwise comparisons between FP use and FP not use (exposed and unexposed) the ORs will vary widely around the average OR (ie, a large $80 \%$ IOR). However, when the residual cluster variance is small, then the variability of the ORs will also be small (ie, a small $80 \%$ IOR). The value of IOR may or may not include 1 . It should be noted that the cluster variability is large and small in comparison with the effect of the cluster-level variable, respectively, if the IOR contains one or not include one. ${ }^{15}$ POOR is an alternative to the IOR as a measure of the magnitude of the effect of cluster-level variables. Importantly, IOR describes the middle $80 \%$ of the distribution of OR comparing a random cluster from use and not use of FP (exposed to the covariate and a random cluster not exposed to the covariate). It is the proportion of such ORs with the opposite direction to the overall OR. The POOR can take values ranging from $0 \%$ to $50 \%$. If its value is 0 , it indicates that all pairwise OR are in the same direction as the overall cluster-specific OR. And half of the pairwise comparisons between clusters use of FP or not are in the direction opposite to the overall OR for the POOR value of $50 \%$. A larger value for the POOR implies that the association is very heterogeneous. ${ }^{13}$

Inline to the above (IOR and POOR) description of measurement, we have a measure of components of variance (the VPC or ICC)) and of heterogeneity (median OR (MOR)). VPC/ICC represents the proportion of the total observed individual variation in the outcome that is attributable to between-cluster variation. It measures the proportion of total variance that is due to the difference between groups. It is interpreted as the correlation in the outcome between two individuals randomly selected from the same cluster. MOR quantifies the magnitude of the effect of clustering. ${ }^{16}$ Hence, MOR is a measure of heterogeneity mainly depend on between-cluster variance while the VPC (ICC) is a measure of components of variance (clustering) that considers both between-cluster and within-cluster variance. The VPC value ranges from 0 to 1 ; if all subjects in the same cluster exhibited the same response, it has a value of 1 and it would be 0 if there was no within-cluster homogeneity of responses. MOR has a value from 1 to infinity and helps for quantifying the contextual effect is that is on the same scale. In line with this, a PCV was calculated for all models by taking the empty model as a reference point. ${ }^{13}$ Furthermore, the effect of multicolinearity between the predictor variables was checked using tolerance and variance inflation factor. Akaike information criterion (AIC) was used to compare 
and check the goodness of fit of the consecutive models. The model with the lowest value of AIC was considered a better explanatory model that fits the data.

\section{RESULTS}

\section{Individual-level variables}

This study focused on a sample of 33 clusters in the pastoralist community of the Afar region. We included 891 married women in the 33 clusters. A large majority of the respondents $(77.2 \%)$ were unable to read and write a simple sentence. About one-quarter $(24.8 \%)$ of the respondents were living in a polygamous marriage (not a single wife to their husband). Above one-in-two $(51 \%)$ respondents were living within a walking distance of 1 hour and more to the nearest health facility. Most respondents $(75.1 \%$ ) had a short birth interval (within 2 years interval) in their two consecutive births. One-third (32.2\%) of the respondents had five and more children. The proportion of respondents who had an abortion in their lifetime was $21.7 \%$. A considerable number of respondents $41.0 \%$ and $67.6 \%$ had no ANC visit and gave their last birth at home, respectively. Almost half $(45.7 \%)$ of the respondents had a high intention to use FP (table 1). The mean value of attitude towards FP use was $40.7(39.2,42.1)$, while it was $40.7(39.4,42.2)$ for the perceived behavioural control over FP use.

\section{Community-level variables}

A total of 33 clusters were considered as a unit of analysis. The community-level variables were formed by aggregating the individual-level variables. Accordingly, 30.3, $60.6 \%$ and $54.5 \%$ of the clusters had lower health facility coverage, lower women decision making on FP, and lower discussion among couples on FP, respectively. Above half $(54.5 \%)$ of the clusters had higher women norms on the number of children for the couples. Besides, $60.6 \%$ of the cluster belongs to lower electronic media possession (table 2).

\section{Multivariable multilevel analyses \\ FP use}

In our study, the current use of FP among the respondents was $18.74 \%(16.34 \%-21.43 \%)$.

Estimated variance components, IOR, median OR, proportional change invariance and POOR of the model

To analyse the effects of pastoralist married women's individual characteristics and community-level factors in FP use, a two-level mixed-effects logistic regression model was used. As illustrated in table 3 for the empty model, $19.4 \%$ of the total variance in the odds of using FP attributed to the between-cluster variation $(\mathrm{ICC}=0.194)$. The ICC or the between-cluster variability declined across the individual factors, community factors and combined level factors model with a value of 12.1, 7.04 and $4.0 \%$, respectively. Hence, to describe the factors related to FP use among the pastoralist married women,
Table 1 Selected individual-level variables of respondents, Ethiopia, 2018

\begin{tabular}{|c|c|c|c|}
\hline Individual characteristics & $\mathbf{N}$ & $\%$ & $95 \% \mathrm{Cl}$ \\
\hline \multicolumn{4}{|l|}{ Educational status of women } \\
\hline Not Able to read and write & 688 & 77.2 & 74 to 79 \\
\hline Able to read and write & 203 & 22.7 & 20 to 25 \\
\hline \multicolumn{4}{|l|}{ Single wife to her husband } \\
\hline No & 221 & 24.8 & 12.1 to 47.6 \\
\hline Yes & 670 & 75.1 & 72 to 77 \\
\hline \multicolumn{4}{|c|}{$\begin{array}{l}\text { Time taken to reach the nearest health facility through } \\
\text { walking }\end{array}$} \\
\hline Less than 1 hour & 430 & 48.2 & 44 to 51 \\
\hline 1 hour and above & 461 & 51.8 & 48 to 55 \\
\hline \multicolumn{4}{|l|}{ The current no of children } \\
\hline $1-4$ & 540 & 67.7 & 63 to 70 \\
\hline 5 and above & 264 & 32.3 & 29 to 36 \\
\hline \multicolumn{4}{|l|}{ Birth interval } \\
\hline Short & 495 & 70.4 & 66 to 73 \\
\hline Optimal & 208 & 29.5 & 26 to 33 \\
\hline \multicolumn{4}{|l|}{ History of having an abortion } \\
\hline No & 632 & 78.2 & 75 to 80 \\
\hline Yes & 176 & 21.7 & 19 to 24 \\
\hline \multicolumn{4}{|l|}{ ANC visit } \\
\hline No ANC visit & 369 & 41.4 & 38 to 44 \\
\hline 1-3 ANC visit & 277 & 31.1 & 28 to 34 \\
\hline 4 and above ANC visit & 245 & 27.5 & 24 to 30 \\
\hline \multicolumn{4}{|c|}{ Place of delivery for the last child } \\
\hline Home & 533 & 67.6 & 64 to 70 \\
\hline Health facility & 255 & 323 & 29 to 35 \\
\hline \multicolumn{4}{|l|}{ Knowledge on FP } \\
\hline Low knowledge on FP & 422 & 47.3 & 44 to 50 \\
\hline High knowledge of FP & 469 & 52.6 & 49 to 55 \\
\hline \multicolumn{4}{|l|}{ Intention to use of FP } \\
\hline Low intention & 483 & 54.2 & 50 to 57 \\
\hline High intention & 408 & 45.7 & 42 to 49 \\
\hline
\end{tabular}

ANC, antenatal care; FP, family planning.

a combined model of individual and community factors were used. The PCV of the combined factors was $98 \%$ $(\tau=0.01385)$. To mean that, $98 \%$ of the predicting use of FP in the pastoralist community can be explained using the reported individual and community-level factors. Similarly, a shrinkage factor was calculated for having a better interpretation of the intra-cluster association in the cluster/community level factor because the value of the cluster level variable is constant for all individuals in the cluster. The shrinkage factor helps to suit the conditional interpretation of the regression coefficients with population average ORs (the average OR comparing two individuals from two different clusters who are identical in 


\begin{tabular}{|c|c|c|c|}
\hline $\begin{array}{l}\text { Community } \\
\text { characteristics }\end{array}$ & $\begin{array}{l}\text { No of } \\
\text { women (\%) }\end{array}$ & $95 \% \mathrm{Cl}$ & $\begin{array}{l}\text { No of } \\
\text { clusters }\end{array}$ \\
\hline \multicolumn{4}{|c|}{ Health facility availability in the cluster } \\
\hline Lower & $270(30.3)$ & 27.3 to 33.3 & 10 \\
\hline Higher & $621(69.7)$ & 66.6 to 72.6 & 23 \\
\hline \multicolumn{4}{|c|}{ Community decision making on FP use made by women } \\
\hline Lower & $540(60.7)$ & 57.3 to 63.7 & 20 \\
\hline Higher & $351(39.3)$ & 36.2 to 42.6 & 13 \\
\hline \multicolumn{4}{|c|}{ Community discussion on FP } \\
\hline Lower & $486(54.5)$ & 51.2 to 57.7 & 18 \\
\hline Higher & $405(45.5)$ & 42.2 to 48.7 & 15 \\
\hline \multicolumn{4}{|c|}{ Women norms on the no of children for the couples } \\
\hline Lower & $405(45.5)$ & 42.2 to 48.7 & 15 \\
\hline Higher & $486(54.5)$ & 51.2 to 57.7 & 18 \\
\hline \multicolumn{4}{|c|}{ Community electronic media possession } \\
\hline Lower & $540(60.7)$ & 57.3 to 63.7 & 20 \\
\hline Higher & 351 (39.3) & 36.2 to 42.6 & 13 \\
\hline
\end{tabular}

FP, family planning.

other respects or apart from the covariate of interest). In the community factor or model 3 , the shrinkage value was 1.042 which is nearly 1 . This indicates that the population average ORs for the five clusters/community factors are essentially equal to the conditional or cluster-specific ORs (to two decimal places). Moreover, the $80 \%$ IOR for the five community-level factors in model 3 were $(2.28,3.5)$ for lower vs higher electronic media possession, (1.62, 2.49) for lower versus higher health facility coverage, $\left(\begin{array}{ll}6.7,1 & 0.3)\end{array}\right)$ for lower versus higher women decision making on FP, $(2.00,3.06)$ for lower vs higher discussion among couples and $(0.27,0.41)$ for lower versus higher women norms on the number of children for couples to have. Overall, the effect of the cluster/community level variable is large in comparison with the unexplained between-cluster variation.

Furthermore, the POOR of the community factors value was 0.00002 for community electronic media possession, 0.000023 for community discussion on FP, 0.00001 for community health facility coverage, 0.0003 for women norms on the number of children and 0.00002 for women decision making on FP. Thus, in $0.002 \%$ of comparison between the community with lower and higher electronic media possession, the OR for this comparison would be different in direction to that of the overall OR for community level, electronic media possession (2.84) denotes an increased FP use (table 4). Moreover, in $0.002 \%$ pairwise comparison, the odds of FP use would be higher at the community with higher electronic media possession than at lower electronic media possession. Additionally, in our model the median OR (MOR) was equal to 2.338 (empty model), 1.902 (individual factors), 1.610 (community factors) and 1.118 (combined model). Hence, for the individual factors, the MOR was 1.901 whereas its reciprocal was 0.52 . Therefore, examining the OR for individual factors in table 4 , nine of the individual factors had an OR that lay outside of the interval $(0.52,1.901)$. Thus, the magnitude of the effect of clustering (cluster effect) was smaller than that of 9 of the 13 individual factors. Hence, the MOR of 1.901 interpreted as fair because only $12.1 \%$ of the total variation in pastoralist married women FP use is due to cluster difference.

\section{Effect of individual women characteristics on the FP use}

The individual and community factors effect size on FP use as described in table 4 . After adjusting for the individual and community factors, married women who gave birth at a health facility for their last birth were more likely to report FP use (AOR 2.71, 95\% CI 1.27 to 5.81) as compared with women who gave their last birth at home. Similarly, women who had 1-3 or 4 or more ANC visits were also more likely to report FP use (AOR 3.6, 95\% CI 1.08 to 11.9 ) and (AOR $6.02,95 \%$ CI 1.74 to 20.8 ), respectively, as compared with married who do not have ANC visit for their recent pregnancy. Women who reported having five or more children and those reporting to walk more than 1 hour to the nearest health facility were 4.71 times and 0.141 more likely to use FP, respectively, as compared with women who had 1-4 children (AOR 4.71, 95\% CI 1.86 to 11.9 ) and walking distance of less 1 hour to the nearest health facility (AOR $0.141,95 \%$ CI 0.05 to 03 ). Moreover, married women with high knowledge on FP and high intention to use FP were more likely to report FP use (AOR 2.74, 95\% CI 1.11 to 6.74 ) and (AOR $10.3,95 \%$ CI 3.85 to 27.6 ), respectively, as compared with married women who had low knowledge and low intention to use of FP, respectively. The net odds of FP use among married women who had an optimal birth interval for their last consecutive birth was 2.65 times (AOR 2.65, $95 \%$ CI 1.24 to 5.64) as compared with married women who had a short birth interval. In line with this, as attitudes supportive of FP use and perceived behavioural control over the negative pressures of influential groups increased by one unit, the odds of FP use increased by 1.24 (AOR 1.24, 95\% CI 1.13 to 1.37) and 1.11(AOR 1.11, $95 \%$ CI 1.03 to 1.2 ), respectively (table 4 ).

\section{Effect of community-level factors/characteristics on the FP use}

Accordingly, after controlling the effect of individual and community factors, cluster with higher discussion among couples on FP, higher women's norm on the number of children for couples to have and higher women's decision making on FP associated with higher odds of FP use (AOR 2.48, 95\% CI 1.02 to 6.72), (AOR 0.34, 95\% CI 0.13 to 0.84 ) and (AOR 8.35, 95\% CI 2.57 to 27.1), respectively as compared with cluster who have a lower discussion among couples on FP, lower women's norm on the number of children for a couple to have and lower women decision making on FP, respectively (table 4). 
Table 3 Estimated variance components, IOR, MOR, POOR in the opposite direction of respondents, Ethiopia, 2018

\begin{tabular}{|c|c|c|c|c|c|c|c|}
\hline \multirow[b]{2}{*}{ Variable } & \multirow[b]{2}{*}{ Empty model } & \multicolumn{2}{|c|}{ Individual factors } & \multicolumn{3}{|c|}{ Community factors } & \multirow[b]{2}{*}{$\begin{array}{l}\text { Combined } \\
\text { factors }\end{array}$} \\
\hline & & $\begin{array}{l}\text { IOR } \\
\text { lower }\end{array}$ & $\begin{array}{l}\text { IOR } \\
\text { upper }\end{array}$ & $\begin{array}{l}\text { IOR } \\
\text { lower }\end{array}$ & $\begin{array}{l}\text { IOR } \\
\text { upper }\end{array}$ & POOR & \\
\hline \multicolumn{8}{|l|}{ Individual-level factors } \\
\hline Being a single wife to her husband & & 0.88 & 1.32 & & & & \\
\hline Institutional delivery & & 2.17 & 3.33 & & & & \\
\hline Having five and more children & & 3.8 & 5.83 & & & & \\
\hline 1-3 ANC visit & & 2.9 & 4.45 & & & & \\
\hline Four and above ANC visit & & 4.83 & 7.41 & & & & \\
\hline $\begin{array}{l}\text { Walking distance within } 1 \text { hour to the } \\
\text { nearest health facility }\end{array}$ & & 0.11 & 0.17 & & & & \\
\hline High knowledge of FP & & 2.19 & 3.36 & & & & \\
\hline Perceived behavioural control over FP use & & 0.90 & 1.38 & & & & \\
\hline Attitude towards FP use & & 1.006 & 1.54 & & & & \\
\hline High intention to FP use & & 8.30 & 12.72 & & & & \\
\hline Able to read and write simple sentences & & 1.62 & 2.49 & & & & \\
\hline Having an abortion in a lifetime & & 0.58 & 0.89 & & & & \\
\hline Having a short birth interval & & 2.13 & 3.26 & & & & \\
\hline \multicolumn{8}{|l|}{ Community-level factors } \\
\hline Higher electronic media possession & & & & 2.28 & 3.5 & 0.00002 & \\
\hline Higher discussion on FP & & & & 2.00 & 3.06 & 0.00002 & \\
\hline Higher women decision making on FP & & & & 6.7 & 10.3 & 0.00001 & \\
\hline $\begin{array}{l}\text { Higher women norms on the number of } \\
\text { children }\end{array}$ & & & & 0.27 & 0.41 & 0.0003 & \\
\hline Higher health facility coverage & & & & 1.62 & 2.49 & 0.00001 & \\
\hline PCV & Ref & 0.37 & & 0.63 & & & 0.98 \\
\hline VPC or ICC & 0.194 & 0.121 & & 0.0704 & & & 0.004 \\
\hline MOR & 2.338 & 1.902 & & 1.610 & & & 1.118 \\
\hline Shrinkage factor & 1.128 & 1.075 & & 1.042 & & & 1.0023 \\
\hline AIC & 822.4 & 260.1 & & 806 & & & 252.5 \\
\hline
\end{tabular}

AIC, Akaike information criterion; ANC, antenatal care; FP, family planning; ICC, intraclass correlation coefficient; IOR, interval OR; MOR, median OR; PCV, proportional change of the variance; POOR, the proportion of OR in the opposite direction; VPC, variance partition coefficient.

\section{DISCUSSION}

Our study revealed that only less than 2-in-10 pastoralist married women currently use FP. Such a proportion of FP users attributed to individual and community-level factors. To mention the individual factors, time taken to the nearest health facility, have five or more children, had an optimal birth interval, the number of ANC visit, have birth at health institution, have high knowledge on FP, positive attitude towards FP, high perceived behavioural control over FP use and had high intentions to use FP. At the community level, three variables namely clusters having higher electronic media possession, higher women's norm on the number of children for a couple to have, and higher support of women's decision making on FP significantly associated with increased FP use compared with clusters with lower reports of these aspects. Besides, to the description of the result of multivariable analysis with OR, a summary measures of the effect of cluster variables (interval IOR, POOR), the PCV and measures of components of variance and heterogeneity (the VPC or ICC and median OR) was calculated to make our result more informative and explanatory.

Nearly 2-in-10 of married women in our study currently use FP. This is in line with a study done in pastoralist women in the Bale eco-region, Southeast Ethiopia. ${ }^{17}$ However, a little bit higher with previous studies done in the pastoralist area. ${ }^{6} 71118$ Differing from this, 4-in-10 women in Ethiopia currently uses FP. ${ }^{49}$ Additionally, other small pocket studies in Ethiopia revealed that a higher proportion of women uses FP. ${ }^{19}{ }^{20}$ This implies further effort is needed to enhance FP use in the pastoralist community. Importantly, it will contribute to the 
Table 4 Estimated ORs for multilevel logistic regression model of FP use of respondents, Ethiopia, 2018

OR $(95 \% \mathrm{Cl})$

\begin{tabular}{|c|c|c|c|c|}
\hline Variable & $\begin{array}{l}\text { Empty } \\
\text { model }\end{array}$ & Individual factors & Community factors & Combined factors \\
\hline \multicolumn{5}{|l|}{ Individual-level factors } \\
\hline Institutional delivery & & $2.85(1.32 \text { to } 6.18)^{\star \star}$ & & $2.71(1.27 \text { to } 5.81)^{\star}$ \\
\hline Having five and more children & & $3.82(1.56 \text { to } 9.33)^{\star \star}$ & & $4.71(1.86 \text { to } 11.9)^{\star \star}$ \\
\hline 1-3 ANC visit & & $4.89(1.42 \text { to } 16.8)^{*}$ & & $3.6(1.08 \text { to } 11.9)^{*}$ \\
\hline $\begin{array}{l}\text { Walking distance within } 1 \text { hour and above to the } \\
\text { nearest health facility }\end{array}$ & & $0.22(0.08 \text { to } 0.58)^{\star *}$ & & $0.141(0.05 \text { to } 0.3)^{\star \star \star}$ \\
\hline High knowledge of FP & & $2.48(1.03 \text { to } 5.95)^{\star}$ & & $2.74(1.11 \text { to } 6.74)^{\star}$ \\
\hline Perceived behavioural control over FP use & & $1.10(1.03 \text { to } 1.18)^{\star *}$ & & $1.11(1.03 \text { to } 1.2)^{\star *}$ \\
\hline Attitude towards FP use & & $1.25(1.14 \text { to } 1.38)^{\star \star \star}$ & & $1.24(1.13 \text { to } 1.37)^{\star \star *}$ \\
\hline Having a short birth interval & & $2.33(1.11 \text { to } 4.89)^{\star}$ & & $2.65(1.24 \text { to } 5.64)^{\star}$ \\
\hline \multicolumn{5}{|l|}{ Community-level factors } \\
\hline Higher electronic media possession & & & 1.07 (0.58 to 1.99$)$ & $2.84(1.2 \text { to } 6.72)^{*}$ \\
\hline Higher discussion among couples on FP & & & 0.59 (0.33 to 1.05$)$ & $2.48(1.02 \text { to } 6.05)^{*}$ \\
\hline Higher health facility coverage in the cluster & & & $3.33(1.49$ to 7.43$)$ ** & 2.01 (0.48 to 8.39$)$ \\
\hline $\begin{array}{l}\text { Higher women's norm on the number of children } \\
\text { for a couple to have }\end{array}$ & & & 1.48 (0.8 to 2.74$)$ & $0.34(0.13 \text { to } 0.84)^{\star}$ \\
\hline Higher women decision making on FP & & & $1.00(0.50$ to 1.98$)$ & $8.35(2.57 \text { to } 27.1)^{\star \star *}$ \\
\hline
\end{tabular}

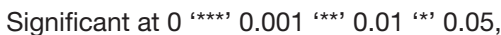

ANC, antenatal care; FP, family planning.

achievement of the national and international goals on FP by narrowing the huge gap between the agrarian and the pastoralist community.

Our study revealed that the time taken to reach the nearest health facility through walking was positively associated with FP use. In line with this, another research output indicates that long distance to the health facility limits FP use. ${ }^{20}$ This would help to convey a tailored and appropriate message of using access to $\mathrm{FP}$ by women through increasing contact with health professionals to enhance husbands' and communities' acceptance of the benefits of FP.

Women from the cluster who had higher electronic media possession were associated with FP use. Our finding is in line with another study in the pastoralist community of the Afar region. ${ }^{11}$ It should be noted that the media programme in the region and the broadcast at the national level with the focus of promoting FP use may encourage women to use FP. Despite the media promotion in the broadcast on FP, the overall infrastructure in the pastoralist community is not well established and does not contribute to its threshold in creating awareness for the women who reside in a remote area.

This study points out that pastoralist women who had a high number of children were positively associated with
FP use. These findings are in line with another study done in Bale eco-region, Southeast Ethiopia. ${ }^{20}$ Clearly, as it was indicated from the community-level variables women who reside in a cluster with lower women's norm on the number of children had higher odds of FP use. Similarly, a study in the pastoralist region revealed that a positive association existed between women who were undecided on when to have their next child and $\mathrm{FP}^{7}$ In this case, as the women have a higher number of children, they may feel the burden and risks associated with frequent childbirth and child-rearing. As a result, the mother's contributions to the economic development of the household, community and the country would be limited.

Our finding revealed a positive association between FP use and women who had an optimal birth interval in their last consecutive birth. Importantly, having a short birth interval would endanger the lives of the mother as well as her newborn. ${ }^{21}$ However, a study in the Bale eco-region, South East Ethiopia indicates that having a short birth interval in the last consecutive children was positively associated with FP use. ${ }^{20}$ This implies the pastoralist women in our study embedded in strong cultural and religious perspectives which promotes to have a high number of children and this leads them to follow short birth intervals. And a considerable 
proportion of women are currently experiencing polygamous marriage and this results to enforce married women to have a high number of children. This is one of the cultural manifestations of respecting the needs of the husband and the pride of winning the competition with the other wives. Moreover, a considerable number of women could not read and write a simple sentence. Hence, such collective influence (being polygamous and illiterate) makes the women normalise and positive reinforcement for giving birth with closed/short birth intervals. However, for a woman who is aware of the benefit of the optimal birth interval, they try to practice it by using FP as they learn from real-life experience was evident in our study.

In our study, FP use was positively associated with an ANC and health facility delivery. That is, pastoralist married women who have ANC visits of 1-3 and have ANC visits of 4 and above associated with FP use. This was in line with studies done elsewhere. ${ }^{22}{ }^{23}$ WHO recommends that a woman should have ANC visits of 4 and above in the course of pregnancy. Moreover, currently WHO recommends a woman to have at least eight ANC visits. ${ }^{24}$ Regarding institutional delivery, our finding was in line with a study done in urban Uttar Pradesh, India. ${ }^{23}$ Therefore, as the women's contact with health providers increases, the probability of obtaining information and informed consent on FP would be improved. Thus, the women who get a golden opportunity to the awareness of $\mathrm{FP}^{10}$-would be vital to fill the missed opportunity. Hence, such collective effort would contribute to increase the women's intention and actual use of FP.

Our finding revealed a positive association of FP use with women's knowledge. Such, finding is also supported by a study done in Mekelle, Tigrai region. ${ }^{25}$ This implies that knowledge is a prerequisite for FP use. To use FP, a woman should first be equipped with comprehensive knowledge on FP which encourages a positive attitude and enhance intention on FP.

A study in the pastoralist community of Afar revealed that having a positive attitude towards FP positively associated with FP use. ${ }^{11} 26$ This was similar to our finding. Importantly, attitude is a proximate indicator of having/ showing a behaviour which is FP use in our scenario by mitigating the myths and misconceptions on FP, creating a conducive environment on the information and relationship between the healthcare providers and women. As a consequence, a continuous effort is needed in the pastoralist community through the community-based structure like faema (a traditional community structure which serves as a social support group and justice) ${ }^{27}$ and government structure for sustaining the current users of FP and to create a new adopter for FP.

Previous studies in the pastoralist community mentioned that husband objection and religious norms promote a high number of children, and this unquestionably negatively influence FP use. ${ }^{28}{ }^{29}$ It should be noted that enhancing the perceived behavioural control over
FP use (the ease of the women for any challenges related to FP comes from influential groups; husband, clan and religious leader) would have a contribution to increasing the proportion of women who use FP. As a consequence, the women's ability to tolerate the pressure that comes from the influential groups would be increased and the women would get an opportunity to use FP. Proof of this, a study in pastoralist women of the Bale eco-region indicates that a positive relationship exists between the perceived cultural acceptability and FP use ${ }^{17}$ However, a study in Niger shows that perceived behaviour control positively predicts over woman resides in an urban area than rural. ${ }^{26}$ Such variation in residence can be explained as that fact of huge difference for the women access to school, and exposure to media which both promote FP use. Also, having concentrated health facilities in urban areas favours women to get information and service at a convenient time.

As part of the cluster effect, married women who had decision making on FP use was associated with FP use. Our study was in line with a finding from pastoralist women of the Bale eco-region ${ }^{17}$-and Mozambique. ${ }^{30}$ The overall activity of women education, providing informed consent and FP use leads to empowering women. As a result, they would have children by choice not by chance, participating in the income-generating activity, in turn, have a direct effect on increasing the economic status of the household, the community and the country as large. It should be noted that supporting women's economic empowerment in the pastoralist community would narrow the health indicators gap including FP with the agrarian society to meet the national and international goals set by the country. For instance, Ethiopia sets an ambitious plan to have a CPR of $55 \%$ and a total fertility rate of 3 by the year $2020 .{ }^{31}$

A positive relation appears across the intention to use FP with actual use. A similar finding revealed that contraceptive use is high per the stated intention to use contraceptives. ${ }^{26}{ }^{32}$ It should be noted the overall effort in disseminating information and counselling women on FP to create a positive attitude towards FP and high intention. Hence, these cumulative effects bring or predict the actual use of FP. This implies a meticulous effort is needed in changing the proportion of women who intend to the actual use of FP. For this reason, the overall activity in health facility including FP counselling should be given based on informed consent. And it should be given with good quality to have the mother optimal birth interval, a desired number of children, and enhance the number/ proportion of FP users.

Furthermore, out of the normal interpretation of multilevel analysis using OR and reporting PCV and VPC/ICC, it includes a summary measures of the effect of cluster variables and measures of components of heterogeneity. In this case, the magnitude of the effect of clustering (cluster effect) for FP use was smaller than that of individual factors. However, a considerable number of the variation to the FP use ascribed to cluster difference. Hence, 
it is important to consider the local/ground situation of a community for promoting better use of FP. FP use can be affected by individual and community level factors. It should be noted that the pastoralist women lived in multifaced factors and addressing such factors would enhance FP use. To conclude, a considerable number of women still use FP in an area where there were strong religious and cultural perspectives. Hence, such a result along with the individual factors, the effect of community/clusterlevel factors is not minimal. At the end, the result of our study will be generalised to pastoralist married women aged 15-49 years. However, our finding should be interpreted while considering the following limitation (1) due to the limited number of clusters, the desired effect is not explicitly described as having high number of clusters (2) our result is limited to the married women aged between 15 and 49 and do not include women who are single, divorced and widowed which may have an effect on quantifying the actual number of FP users (3) Since we employed a cross-sectional study to answer the objectives, it makes the examination of causal effect relationship difficult.

\section{CONCLUSION}

FP use among the pastoralist community is influenced by both individual and cluster/community level characteristics or factors. Even though the effect of clustering (cluster effect) on FP use was large in comparison with the unexplained between-cluster variation, it was lower than the individual-level factors.

Acknowledgements We are grateful to thank the data collectors, supervisor, and study participants for the successful accomplishment of the study. Also, we would like to thank the faema leaders, healthcare providers and religious leaders participating in the provision of the intervention. Finally, we would like to thank, Afar regional health bureau, Mekelle University, DFID and FMOH.

Contributors MA contributed to the initiation of the study, design, data collection, data analysis and write up. AAM and AM contributed to the initiation of the study, design and write up. ER contributed to the interpretation of the findings and write up of the manuscript. All authors read and approved the final manuscript.

Funding This study was conducted with the financial support of the Federal Ministry of Health of Ethiopia (FMOH) through the generous support of the Development for International Development (DFID) in the Reproductive Innovative Fund (RIF) project.

Disclaimer The Funders has no role in the design, analysis, and dissemination of the finding.

\section{Competing interests None declared.}

Patient and public involvement Patients and/or the public were not involved in the design, or conduct, or reporting, or dissemination plans of this research.

\section{Patient consent for publication Not required.}

Ethics approval The Institutional Review Board (IRB) of Mekelle University College of Health Sciences approved the study protocol with a reference number of ERC 1435/2018. Permission was obtained from all relevant authorities in the Afar regional health bureau and participating district health offices.

Provenance and peer review Not commissioned; externally peer reviewed.

Data availability statement All data relevant to the study are included in the article or uploaded as online supplementary information. Data are available in the manuscript.
Open access This is an open access article distributed in accordance with the Creative Commons Attribution Non Commercial (CC BY-NC 4.0) license, which permits others to distribute, remix, adapt, build upon this work non-commercially, and license their derivative works on different terms, provided the original work is properly cited, appropriate credit is given, any changes made indicated, and the use is non-commercial. See: http://creativecommons.org/licenses/by-nc/4.0/.

ORCID iD

Mussie Alemayehu http://orcid.org/0000-0002-0035-631X

\section{REFERENCES}

1 WHO. Family planning/contraception, 2018. Available: https://www. who.int/news-room/fact-sheets/detail/family-planning-contraception [Accessed 8 Feb 2018].

2 Swallow B. The role of mobility within the risk management strategies of pastoralists and Agro-Pastoralists. International Institute for Environment and Development Sustainable Agriculture and Rural Livelihoods Programme Kenya, 1997.

3 AU. "Farmer-Herder Conflicts on the Rise in Africa", 2018. Available: https://www.hrw.org/news/2018/08/06/farmer-herder-conflicts-riseafrica [Accessed 8 Aug 2018].

4 Ethiopian Public Health Institute (EPHI) [Ethiopia], ICF. Ethiopia mini demographic and health survey 2019: key indicators. Rockville, Maryland, USA: EPHI and ICF, 2019.

5 Central Statistical Authority [Ethiopia], ORC Macro. Ethiopia demographic and health survey 2000. Addis Ababa,Ethiopia and Calverton, Maryland, USA: Central Statistical Authority and ORC Macro, 2001.

6 Alemayehu M, Araya AM, Kibrom B, et al. The levels of utilization of reproductive, maternal and neonatal health services among women from pastoralist communities in afar, Ethiopia: across-sectional survey. Ethiop J Health Dev 2018;32:34-42.

7 Afework B, Alemayehu M, Znabu H, et al. Factors influencing contraceptive use among women of reproductive age from the pastoralist communities of afar, Ethiopia: a community-based crosssectional study. Ethiop J Health Dev 2018;32:28-33.

8 Wudneh A, Nigatu D, Dendir Z, et al. Comparative analysis of the cost-effectiveness of natural resource management actions with and without family planning interventions as a means of achieving sustainable resource use in the bale Eco-Region.SHARE bale EcoRegion project. Ethiopia, 2017.

9 Alemayehu M, Medhanyie AA, Bezabih AM, et al. Use of communitybased intervention to promote family planning use among Pastoralist women in Ethiopia: cluster randomized controlled trial. medRxiv 2020:20117093.

10 Central Statistical Agency (CSA) [Ethiopia], ICF. Ethiopia demographic and health survey 2016: key indicators report. Addis Ababa, Ethiopia, and Rockville, Maryland, USA: CSA and ICF, 2016.

11 Alemayehu M, Lemma $\mathrm{H}$, Abrha K, et al. Family planning use and associated factors among pastoralist community of afar region, eastern Ethiopia. BMC Womens Health 2016:16:39.

12 Fishbein M. The role of theory in HIV prevention. AIDS Care 2000;12:273-8.

13 Austin PC, Merlo J. Intermediate and advanced topics in multilevel logistic regression analysis. Stat Med 2017;36:3257-77.

14 Neuhaus JM, McCulloch CE. Separating between- and within-cluster covariate effects by using conditional and partitioning methods. $J$ Royal Statistical Soc B 2006;68:859-72.

15 Larsen K, Merlo J. Appropriate assessment of neighborhood effects on individual health: integrating random and fixed effects in multilevel logistic regression. Am J Epidemiol 2005;161:81-8.

16 Diehr $\mathrm{P}$, Cain $\mathrm{K}$, Connell $\mathrm{F}$, et al. What is too much variation? the null hypothesis in small-area analysis. Health Serv Res 1990;24:741-71.

17 Belda SS, Haile MT, Melku AT, et al. Modern contraceptive utilization and associated factors among married pastoralist women in bale eco-region, bale zone, South East Ethiopia. BMC Health Serv Res 2017;17:194.

18 Bogale A, Mekonnen W. Family planning use and its determinants among Pastoralist communities of Ethiopia. Soc Sci 2017;6:57-62.

19 Medhanyie AA, Desta A, Alemayehu M, et al. Factors associated with contraceptive use in Tigray, North Ethiopia. Reprod Health 2017;14.

20 Gonie A, Wudneh A, Nigatu D, et al. Determinants of family planning use among married women in bale eco-region, Southeast Ethiopia: a community based study. BMC Womens Health 2018;18:50.

21 Subhi R, Ahmed $H$, Mawlood $Z$. Spacing effects on maternal-child health. Tikrit Med J 2011;17:1-6.

22 Abera Y, Mengesha ZB, Tessema GA. Postpartum contraceptive use in Gondar town, Northwest Ethiopia: a community based crosssectional study. BMC Womens Health 2015;15:19. 
23 Achyut P, Mishra A, Montana L, et al. Integration of family planning with maternal health services: an opportunity to increase postpartum modern contraceptive use in urban Uttar Pradesh, India. J Fam Plann Reprod Health Care 2016:42:107-15.

24 WHO. Sexual and reproductive health:New guidelines on antenatal care for a positive pregnancy experience. Geneva, 2016.

25 Alemayehu M, Belachew T, Tilahun T. Factors associated with utilization of long acting and permanent contraceptive methods among married women of reproductive age in Mekelle town, Tigray region, North Ethiopia. BMC Pregnancy Childbirth 2012;12:6.

26 Mayaki F, Kouabenan DR. Social norms in promoting family planning: a study in niger. S Afr J Psychol 2015;45:249-59.

27 Key CW, Araya AM, Mark S, et al. Best practices for addressing socio-cultural barriers to reproductive, maternal and neonatal health service utilization among women from pastoralist communities of afar, Ethiopia: a qualitative study. Ethiop $\mathrm{J}$ Health Dev 2018;32:4-12

28 Peyman N, Oakley D. Effective contraceptive use: an exploration of theory-based influences. Health Educ Res 2009;24:575-85.

29 Hanson JD, Nothwehr F, Yang JG, et al. Indirect and direct perceived behavioral control and the role of intention in the context of birth control behavior. Matern Child Health $J$ 2015;19:1535-42.

30 Mboane R, Bhatta MP. Influence of a husband's healthcare decision making role on a woman's intention to use contraceptives among Mozambican women. Reprod Health 2015;12:8.

$31 \mathrm{FMOH}$. Health sector transformation plan 2015/16 - 2019/20, 2015

32 Ross JA, Winfrey WL. Contraceptive use, intention to use and unmet need during the extended postpartum period. Int Fam Plan Perspect 2001;27:20-7. 